\title{
Effect of exercise on myocardial energy metabolism and relationship between coronary microvascular dysfunction and abnormal myocardial energetics in diabetic cardiomyopathy
}

\author{
Eylem Levelt ${ }^{1,2^{*}}$, Chris Rodgers ${ }^{1}$, William T Clarke ${ }^{1}$, Masliza Mahmod ${ }^{1}$, Rina Ariga ${ }^{1}$, Jane M Francis ${ }^{1}$, Alexander Liu', \\ Cameron Holloway', Matthew D Robson', Kieran Clarke², Theodoros D Karamitsos', Stefan Neubauer ${ }^{1}$
}

From 18th Annual SCMR Scientific Sessions

Nice, France. 4-7 February 2015

\section{Background}

Diabetic cardiomyopathy is a well-recognised entity, with multifactorial aetiology. We and others have previously shown impaired myocardial energetics (decreased $\mathrm{PCr} /$ ATP using cardiac 31P Magnetic Resonance Spectroscopy-MRS) in patients with type II diabetes mellitus (T2DM) at rest. Furthermore, diabetic patients are known to have impaired myocardial perfusion reserve even in the absence of epicardial coronary artery disease likely due to microvascular dysfunction. However, it is unknown whether this hypoperfusion is translated to further energetic derangement at stress.

\section{Methods}

27 patients (13 male, mean age $54 \pm 1.5$ years; BMI $28 \pm 2.7$ ) with T2DM and 24 healthy volunteers of similar age and BMI (13 male, mean age $51 \pm 2.6$ years; BMI $26 \pm 0.84$ ) were studied. Patients were on oral antidiabetic therapies only, with mean HBA1c $7.4 \pm 1.3 \%$ and no history of diabetic complications. Obstructive coronary artery disease (defined as $>50 \%$ lumen diameter reduction) was excluded in all patients by CT coronary angiography. Cardiac 31PMRS (3T) was performed at rest and during 8 minutes of leg exercise lying prone, with $2.5 \mathrm{~kg}$ weights attached to both legs. First-pass perfusion images (using a saturation recovery fast-gradient echo sequence and $0.03 \mathrm{mmol} / \mathrm{kg}$ bolus of Gadoterate meglumine (Dotarem, Guerbet LLC, France ) were also acquired at stress (3-6 minutes i.v. adenosine, $140 \mu \mathrm{g} / \mathrm{kg} / \mathrm{min}$ ) and rest at mid ventricular short

${ }^{1}$ OCMR, University of Oxford, Oxford, UK

Full list of author information is available at the end of the article axis. myocardial perfusion reserve index (MPRI) were measured from perfusion images.

\section{Results}

Left ventricular ejection fraction (LVEF) and mass index (LVMI) were similar in patients with T2DM and healthy volunteers (LVEF $70 \pm 1$ vs $71 \pm 0.9 \%$, $\mathrm{p}=0.494$; LVMI 56.7 \pm 1.8 vs $\left.52.6 \pm 2.4 \mathrm{~g} / \mathrm{m}^{2}, \mathrm{p}=0.168\right)$. Increases in rate pressure product with exercise (T2DM $46 \pm 36 \%$, healthy volunteers $42 \pm 26 \%, \mathrm{P}=0.69)$ and adenosine stress (T2DM $40 \pm 3 \%$, healthy volunteers $39 \pm 3 \%, \mathrm{P}=0.89$ ) were similar. There was no change in $\mathrm{PCr} / \mathrm{ATP}$ during exercise in healthy volunteers (rest: $2.03 \pm 0.05$, exercise: $2.10 \pm 0.09 \mathrm{P}=0.84)$. Resting $\mathrm{PCr} / \mathrm{ATP}$ was reduced in patients $(1.67 \pm 0.04, \mathrm{P}=<0.001)$ compared to controls, and during exercise, there was a further reduction in $\mathrm{PCr} / \mathrm{ATP}(1.52 \pm 0.05, \mathrm{P}=0.037$ vs rest). As expected, myocardial perfusion reserve was significantly reduced in diabetic patients $(1.64 \pm 0.08$ vs $2.1 \pm 0.14$ in controls, $\mathrm{P}=0.002)$. Furthermore, there was a significant correlation between MPRI and exercise energetics $(R=0.401$, $\mathrm{P}=0.015$ ), but not rest energetics.

\section{Conclusions}

During exercise, the pre-existing energetic deficit in diabetic cardiomyopathy is further exacerbated. While myocardial energetics at rest is not related to coronary microvascular dysfunction and is primarily a result of metabolic dysfunction, during exercise, microvascular dysfunction exacerbates the energetic deficit. 

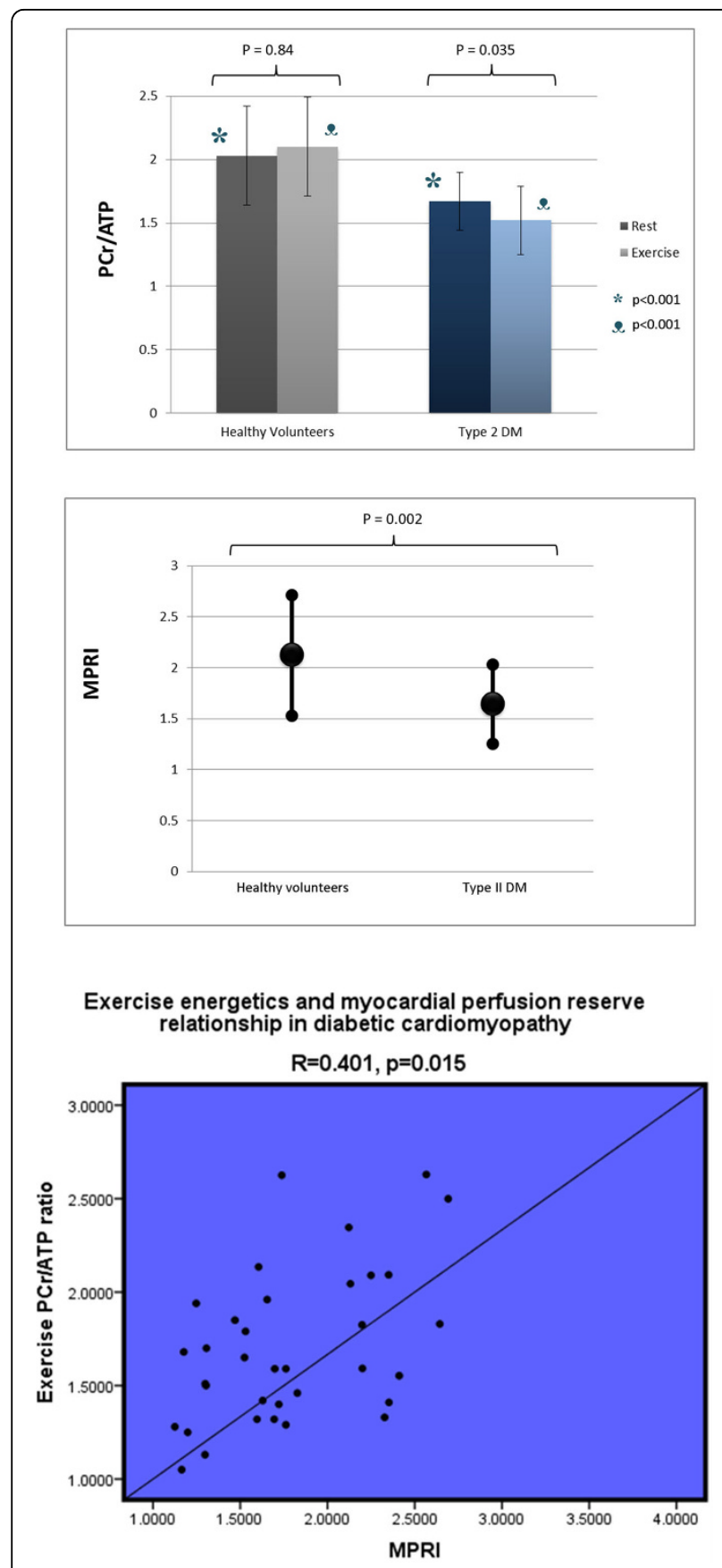

Figure 1 Rest and exercise myocardial energetics and myocardial perfusion reserve assessments in patients with T2DM and healthy volunteers

\section{Funding}

The National Institute for Health Research Oxford Biomedical Research Council and Sir Henry Dale Fellowship from the Welcome Trust and the Royal Society [Grant Number 098436/Z/12/Z] supported this work.

\section{Authors' details}

${ }^{1}$ OCMR, University of Oxford, Oxford, UK. ²Department of Physiology, Anatomy\&Genetics, University of Oxford, Oxford, UK.

Published: 3 February 2015

doi:10.1186/1532-429X-17-S1-098

Cite this article as: Levelt et al:: Effect of exercise on myocardial energy metabolism and relationship between coronary microvascular dysfunction and abnormal myocardial energetics in diabetic cardiomyopathy. Journal of Cardiovascular Magnetic Resonance 201517

(Suppl 1):098.
Submit your next manuscript to BioMed Central and take full advantage of:

- Convenient online submission

- Thorough peer review

- No space constraints or color figure charges

- Immediate publication on acceptance

- Inclusion in PubMed, CAS, Scopus and Google Scholar

- Research which is freely available for redistribution

Submit your manuscript at www.biomedcentral.com/submit 